\title{
The short- $a$ split in a suburban area of the New York City dialect region
}

\author{
Allison Shapp*
}

\begin{abstract}
In American English, the most common pattern for the pronunciation of the allophones of the vowel phoneme /æ/ is the "nasal-split," where the vowel is tense (raised, fronted) when followed by a nasal consonant and lax (lowered, backed) otherwise. In contrast, historically New York City English (NYCE) has had a "complex short- $a$ split" with different conditioning factors for each allophone. This paper reports on new data from the eastern edge of the NYCE dialect region: suburban Nassau County, Long Island. Using word-list data from the sociolinguistic interviews of 24 high school students, aged 14-18, and 7 of their teachers and mentors, this paper shows that while young speakers in this region are moving towards the wider American nasal-split, the local version of that nasal-split still includes components of the traditional NYCE complex-split.
\end{abstract}

Keywords. sociolinguistics; phonetics; sociophonetics; New York City English; Long Island; short- $a$ split; change in progress

1. Introduction. In American English, the low front vowel /æ/ often surfaces with two allophones, a "tense" version (raised and fronted) and a "lax" version (lower and backer). However, there are several different systems of phonological conditioning of these allophones that exist in various dialects. The most common pattern in American English for the pronunciation of $/ æ /$ is known as the "nasal-split." In this system, the vowel is tense when followed by a nasal consonant and lax otherwise. However, New York City English (NYCE) has had a historically "complex split," described in detail below. This study presents data from high school students and their teachers and mentors in Nassau County, a suburban area outside of New York City. While the complex-split has been widespread in this area and is still present, the youngest speakers are starting to move towards the nasal-split common in the majority of the country. However, there are certain constraints of the traditional NYCE complex-split that are still operating on these young speakers' short- $a$ split systems.

2. Short- $\boldsymbol{a}$ in New York City. The split of New York City's short- $a$ into tense and lax sets was described as early as Babbitt (1896), was described further by Trager (1940), and has continued to be discussed extensively by sociolinguists (Cohen 1970, Labov, Yeager and Steiner 1972, Labov 2007, Becker and Wong 2009, Becker 2010, Coggshall 2017). The NYCE complex-split is conditioned primarily by the following environment like the nasal-split; however, the classes of following environments are not nasals versus orals, but are instead front nasals, voiced stops, and voiceless fricatives, which condition a tense short- $a$, versus velar nasals, voiceless stops, and voiced fricatives, which condition a lax short- $a$. See Figure 1 (taken from Labov 2007) for a visual representation of the following environments that condition a tense short- $a$ (shown inside the inner box of the figure), and the following environments that condition a lax short- $a$ (shown in between the outlines of the two boxes).

*Author: Allison Shapp, New York University (allison.shapp@nyu.edu). 


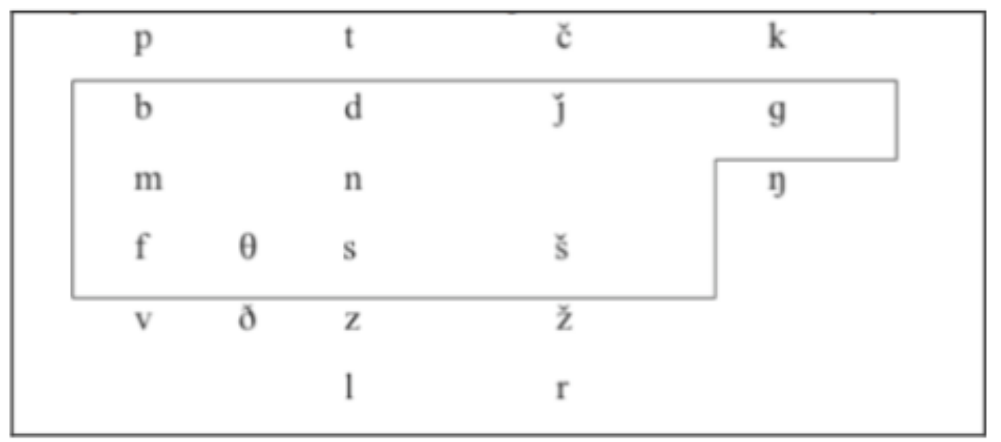

Figure 1. Codas that condition the short- $a$ split in NYCE, organized by place and manner of articulation ${ }^{1}$

2.1. ADDITIONAL CONSTRAINTS. While conditioning by the following phonetic environment is the main determiner of which short- $a$ allophone surfaces in the NYCE complex-split, there are additional patterns and exceptions to be accounted for. After presenting the chart in Figure 1, Labov states: "To this basic condition there are added a number of specific conditions" (354) and enumerates seven such conditions. Each condition describes a situation in which lax variants of short- $a$ are found where they would be expected to be tense given the following environment rules described above, or vice versa. Four of the described conditions are strictly lexical phonology is not the determining factor. These constraints pertain to function words (e.g. "have"), abbreviations (e.g. the nickname "Babs"), lexical exceptions (e.g. "avenue"), and learned words (e.g. "carafe"). The remaining three proposed constraints are phonologically based, and I briefly paraphrase them here.

1) Open-Syllable Constraint: vowels in an open syllable surface as lax where they would be tense if the same following segment were tautosyllabic. For example, the vowel in the word "plan"/plæn/ is tense, but the vowel is lax in "planet," where the word is syllabified as /'plæ.nət/, with the short- $a$ in an open syllable.

2) Inflectional-Boundary Closing: this constraint is an exception to the application of the Open-Syllable Constraint. An inflectional boundary causes the short- $a$ to act as if it is in a closed syllable, rendering the vowel in, for example, "planning" tense, even though it is arguably in an open syllable.

3) Initial Condition: short- $a$ will surface as lax when word-initial even if the following environment would normally condition it as tense, for example in the word "aspirin."

This study makes a case that at least two of these three phonologically based constraints of the NYCE complex-split, namely the Open-Syllable Constraint and the Initial Condition, are operating on the short- $a$ systems of some young speakers in the NYCE dialect region, even as their overall systems move towards a nasal-split. In my analysis below, I use the word PLANET to represent the class of words that the Open-Syllable Constraint would render lax when it would otherwise be tense. I use the word ANT to represent the same for the Initial Condition. For students with a nasal-split, only word-initial vowels with following tautosyllabic nasals would be

\footnotetext{
${ }^{1}$ Figure from Labov 2007:354.
} 
evidence of the Initial Condition, as the oral following environments of voiced stops and voiced fricatives would already be lax, and if the vowel could be considered as in an open syllable, it would be unclear which constraint was at work.

\subsection{CONTINUOUS RAISING AND TRANSITIONAL SHORT-A SYSTEMS. A third possible system} relevant to the NYCE speaking population is a "continuous raising system." In this system, short- $a$ before front nasal codas are the tensest and short- $a$ before voiceless stops are generally the laxest, but there are no significant gaps in the distribution of tokens between these two extremes (Labov 2007, Becker 2010).

Becker (2010) examined the short- $a$ split on the Lower East Side, the same neighborhood about which Labov wrote his seminal work Social Stratification of English in New York City (1966). Through analyzing short- $a$ production in oral history interviews, she found an apparent time effect, with the nasal-split present in many of her younger speakers, while the older speakers retained the NYCE complex-split. She additionally classified 19 out of 64 of her speakers as having a continuous raising system, and these speakers were of ages in between the younger nasal-split speakers and the older complex-split speakers. Becker (2010) also found evidence of a nascent change in the treatment of short- $a$ before velar nasals in the NYCE system. She classified 6 subjects as having a "Labovian Transitional" system. These were middle-aged or older speakers who otherwise had the complex-split as previously described by Labov, but who also exhibited some deviations that Becker describes as "part of the picture of change in short- $a$ in the community" (181). The main example of transitional deviation is the tensing of short- $a$ before velar nasals, which was a lax conditioning environment in previous descriptions.

The subjects in the present study also exhibit a variety of systems that can be classified as a complex-split, a nasal-split, or a continuous raising system, as well as significant raising before velar nasals. The change in progress that Becker found on the Lower East Side, or one very similar, may be underway as well in the present community of study on Long Island.

3. Data collection and measurement methods. The speakers in the present study are from the eastern edge of the NYC dialect region: suburban Nassau County, Long Island. While historical dialectological studies place Nassau as part of the NYC region (Kurath 1949, Labov, Ash, and Boberg 2006), there has been virtually no study of the distribution of NYC features there (but see Olivo 2013).

The present data comes from an academic year that the researcher spent as a participant observer in a high school in Nassau County. The subjects are all students and mentors of the high school's after school robotics team. In this context, mentors include teachers, parents, alumni, and other members of the community that volunteer to teach and guide the students in engineering and other aspects of managing the team. Sociolinguistic interviews were conducted at the end of the research period with 24 students, aged 14-18, and 7 mentors. The adults in this study include 3 teachers employed by the high school and 4 additional mentors who are not affiliated with the school.

The data reported on here consists of 1389 tokens of the /ae/-vowel from the word list portion of these sociolinguistic interviews. The word-list was comprised of 145 items, 47 of which contained short- $a$ tokens. The rest of the tokens were designed to test the LOT/THOUGHT vowels, the phenomenon of $h$-dropping in words like "humid" or "human," or were filler words. Two short- $a$ word-list items were eliminated from the analysis: the word "gaffe" because many students did not know how to pronounce the word upon encountering it, and the word "manning" 
because of semantic interference from the name of the New York Giants quarterback Eli Manning. Six additional short- $a$ tokens were eliminated due to unclear audio.

Interviews were transcribed in ELAN, and then put through the FAVE suite (Rosenfelder et.al. 2011) to align the transcriptions to the recordings and to extract the vowels. The short- $a$ vowels are measured for F1 and F2 at 30\% through the vowel, and are normalized across speakers. Each token was coded for preceding environment, following environment, open or closed syllable status, stress, word-initialness, and for a number of social factors including gender, age, and ethnicity.

The Atlas of North American English (Labov, Ash, and Boberg 2006) gives a threshold of $700 \mathrm{~Hz}$ for $\mathrm{F} 1$ to determine whether a short- $a$ is tense (lower than $700 \mathrm{~Hz}$ ) or lax (higher than $700 \mathrm{~Hz}$ ). However, this guideline does not account for the fronting that occurs in the tense allophone which is represented in F2. The difference between tense and lax varies from speaker to speaker enough that the classifications of short- $a$ split systems in this analysis are gleaned from plotting each speaker's tokens and visually determining if there are two clear clusters with a significant gap, and if so, what description can classify the tokens one either side of the gap (a nasal-split or a NYCE complex-split). If no clear separation is seen, the system is classified as continuous raising.

4. Results. I start by comparing the overall average values of the pronunciation of the short- $a$ vowel amongst the students and amongst their mentors, showing a clear difference wherein the mentors pattern closer to the NYCE complex-split and the students closer to a nasal-split. I then briefly expand upon the variation present amongst the mentors. Next, I turn to demonstrating that among the students, even those with the most advanced nasal-splits, some of the above-described "additional constraints" of the NYCE complex-split are still operating on their pronunciation of short- $a$. Finally, I highlight a unique feature of the NYCE short- $a$ system that is robustly still present: the minimal pair between the word "can" as a noun (as in "tin can") and the word "can" as an auxiliary (as in "I can").

Each vowel plot below shows the values for the pronunciation of short- $a$ before front nasals, velar nasals, voiced fricatives, voiceless fricatives, voiced stops, and voiceless stops. By looking at these six categories, it's possible to see if a subject has a split between a tense and a lax variant, and if so, which following environments correspond to which side of that split. This determines whether the subject has a nasal-split, a NYCE complex-split, or a continuous raising system.

4.1. STUDENTS VS. MENTORS. Even though the mentor group contains a large age range (the youngest mentor is 24 years old and the oldest 86 years old, with the remaining five falling in clusters at 30 years old and 60 years old), there is still a clear difference between their aggregate data and that of the students who are all 18 years old or younger. I tested to see if the 24-year-old mentor skewed the results at all, but the mentor plot below looked almost identical with or without this subject, so I chose to include his data. This is significant because if the move to a nasal-split is a current change in progress, there has been a significant shift in just the short time between the current high school students and at most those at 30 years of age.

Figure 2 below shows an average of short- $a$ pronunciation for all 24 students. A clear split can be seen between the placement of the short- $a$ when followed by nasals (velar or front) and when followed by all other phonemes. In this case, the cutoff for the tense vowels is very close to the $700 \mathrm{~Hz}$ mark mentioned in Labov, Ash \& Boberg (2006). It's also worth noting that the laxest 
(lowest and backest) short- $a$ occurs before voiceless stops, while voiced stops and voiceless fricatives, which would be tense in the complex-split, are a bit higher and fronter.

In Figure 3 below, we see a different result for the mentors. Again, front nasals are the tensest and voiceless stops are the laxest. However, in this plot we crucially see voiced stops and voiceless fricatives clearly patterning with the nasals up in the tense corner of the plot, in contrast to the student plot, where these two points are on the lax side of the split. The mentors' distribution most closely conforms to the NYCE complex-split. While the gap between the two allophones shown in Figure 3 is clear, note that the threshold is not at $700 \mathrm{~Hz}$.

Students: Average Values by Following Environment

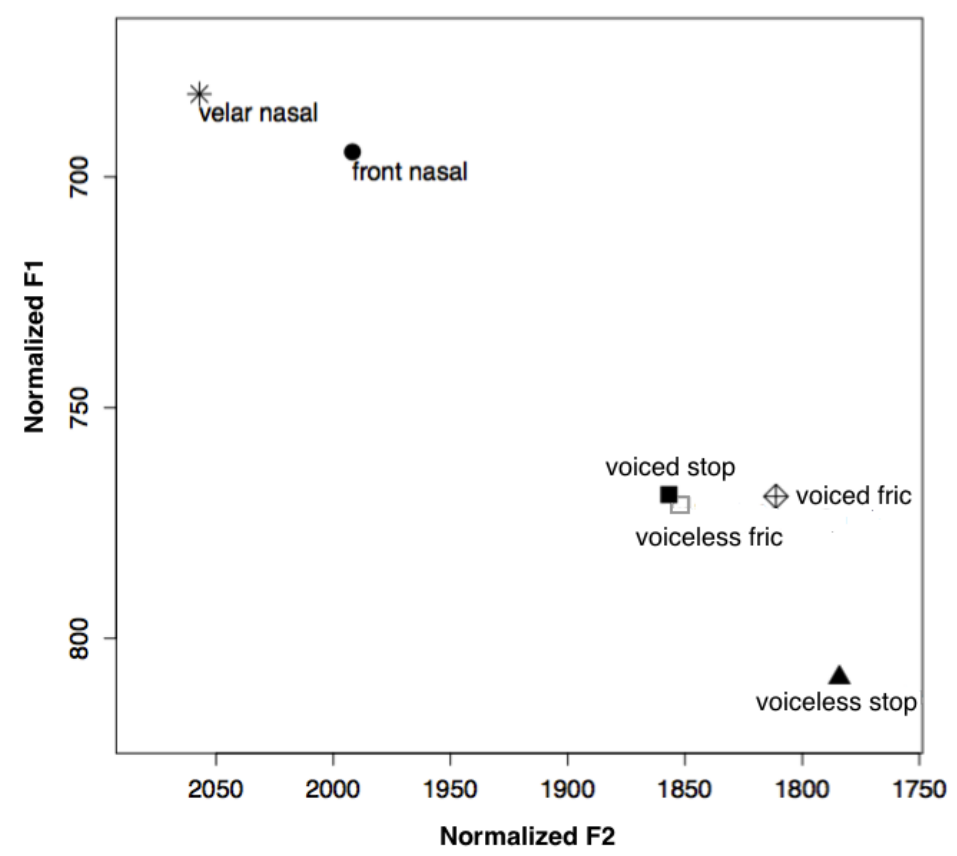

Figure 2. Vowel plot of the students' average pronunciation of short- $a$ before various following environments. 


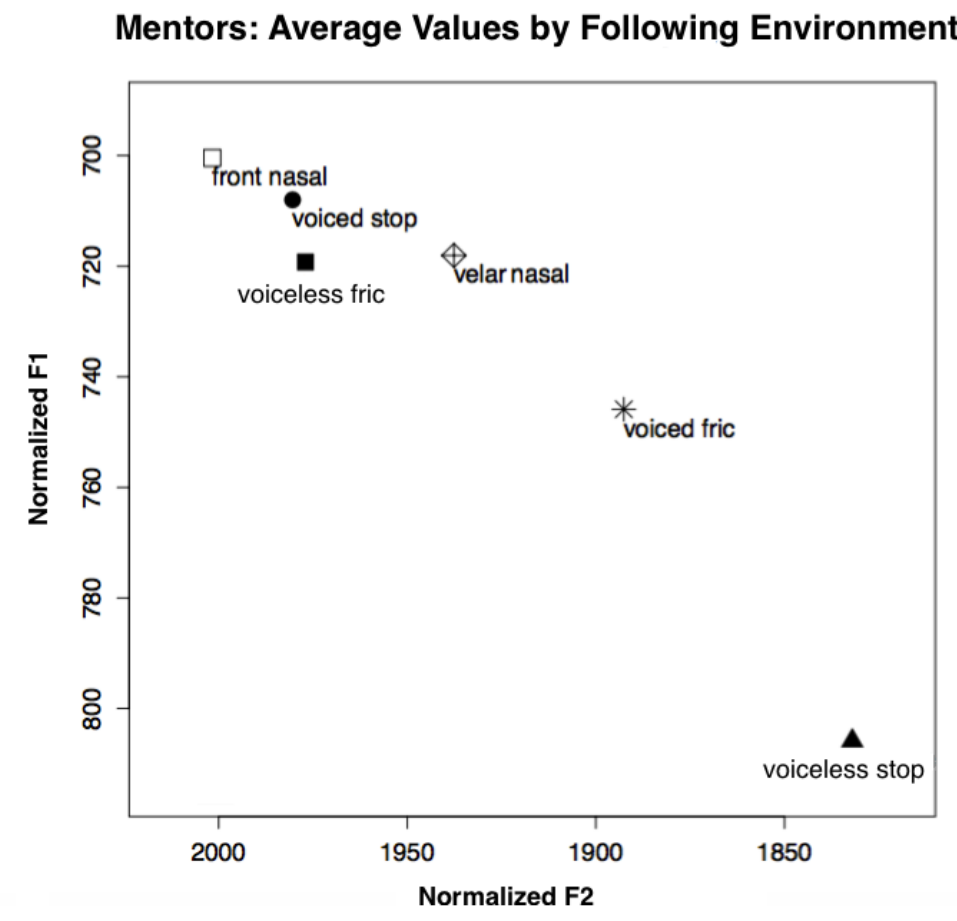

Figure 3. Vowel plot of the mentors' average pronunciation of short- $a$ before various following environments.

4.2. A CLOSER LOOK AT THE MENTORS. In looking at both of the above vowel plots (Figures 2 and 3), it is important to remember that they are averages of speakers who all have somewhat different distributions of this vowel split, especially amongst the 24 students. A more in-depth analysis of individual vowel plots can be found in Shapp (forthcoming). While the chart in Figure 3 is representative on the whole of the 7 mentors, there is some variation to note. First, in the production of short- $a$ before velar nasals. Recall that in the NYCE complex-split, words like "bang" and "sang" would contain a lax short-a, but following Becker's (2010) findings mentioned above, it is not surprising that both the students and the mentors exhibit some degree of tensing before velar nasals. In fact, the mentors are split roughly in half, with 4 speakers having raised short- $a$ before velar nasals, and 3 who maintain a laxer variant in this position.

Another point of variation for the mentors is that while five of the mentors have a NYCE complex-split, two of the mentors have a system that is closer to a continuous raising system. This partially accounts for the large distance between voiced fricatives and voiceless stops in Figure 3 above. Neither point of variation among the mentors, in regard to either velar nasals or continuous raising, seem to line up with age. So while there is an overall age-graded contrast between students and mentors, further analysis is necessary to discover any patterns conditioning these differences beyond age. Figure 4 below shows an example of a continuous raising system from a 30-year-old male mentor. 


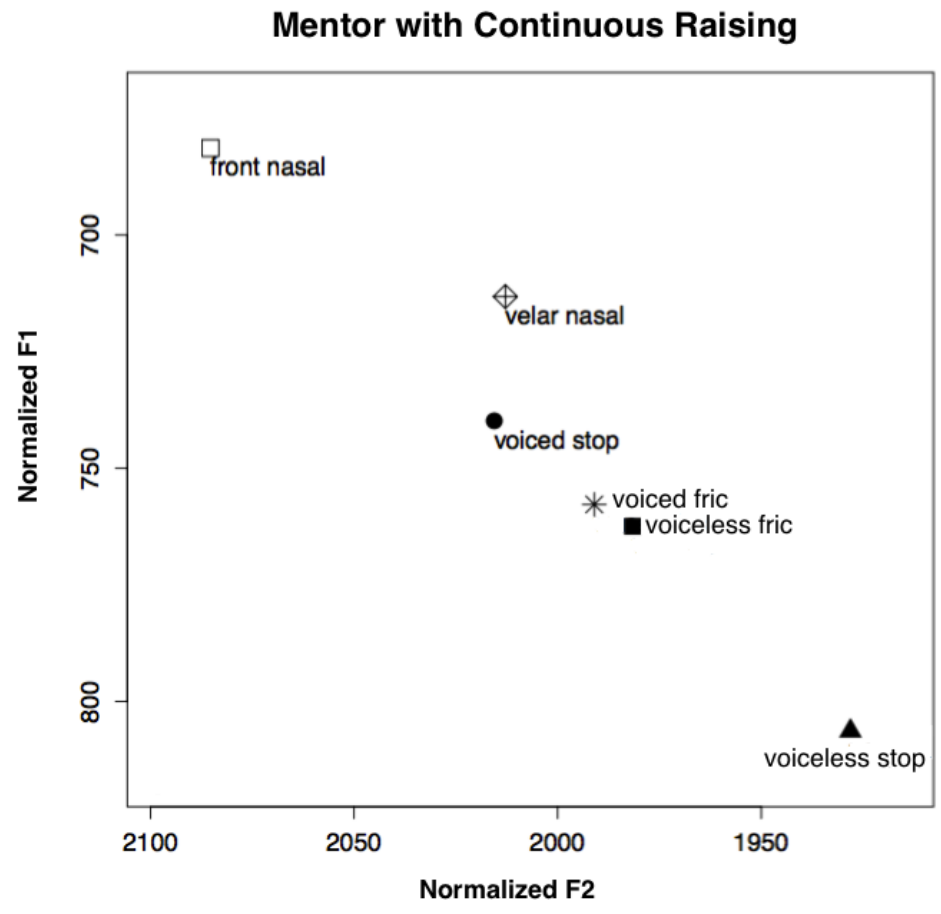

Figure 4. Vowel plot of a short- $a$ continuous raising system

4.3. THE ADDITIONAL CONSTRAINTS IN STUDENTS WITH NASAL-SPLITS. Figure 5 below is a plot of the productions of one subject, a 14-year-old male. This example is chosen as an illustration of the Initial Condition and Open-Syllable Constraint operating within a nasal-split system. Here you can see a distinct split between the vowels followed by nasals (F1>700Hz and front) and all other following environments which are lax (lower and backer). While the voiced stops and voiceless fricatives that would be tense in the NYC system are slightly higher and fronter, they are still clearly in the same area as the voiceless stops and voiced fricatives, and the salient gap is between nasals and non-nasals. This plot also contains data points for words in the PLANET and ANT classes, which represent the Open-Syllable Constraint and Initial Constraint respectively. In these words, the short- $a$ vowel is followed by a nasal, but is not pronounced as tense. This speaker has a primarily nasal-split, but two of the additional NYCE complex-split constraints can be seen to still be operating on the speaker's system. 


\section{Subject Vowel Plot}

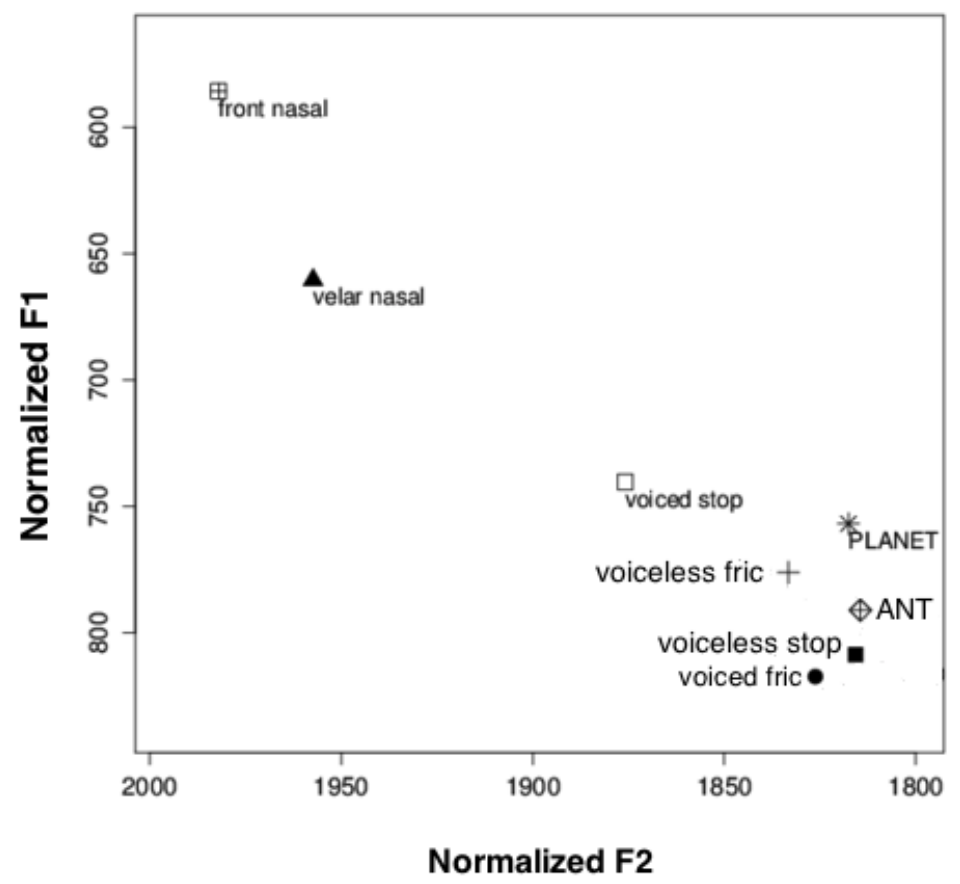

Figure 5. Vowel plot of a nasal short- $a$ split, with PLANET and ANT word classes included

4.4. THE CAN-CAN MINIMAL PAIR. One final finding to highlight is the persistence of the minimal pair between the word "can" as a noun or as an auxiliary. The word list contained the items "I can" and "tin can" to prompt the subjects to produce the word as they would in each context, and almost every subject had a contrast between the two. Figure 6 is the plot of a 15-year-old female subject who has the most distinct nasal-split out of all the students in the study. However, as can be seen in this vowel plot, she still has a significant minimal pair distinction between the auxiliary word ("I can") and the content word ("tin can"). 


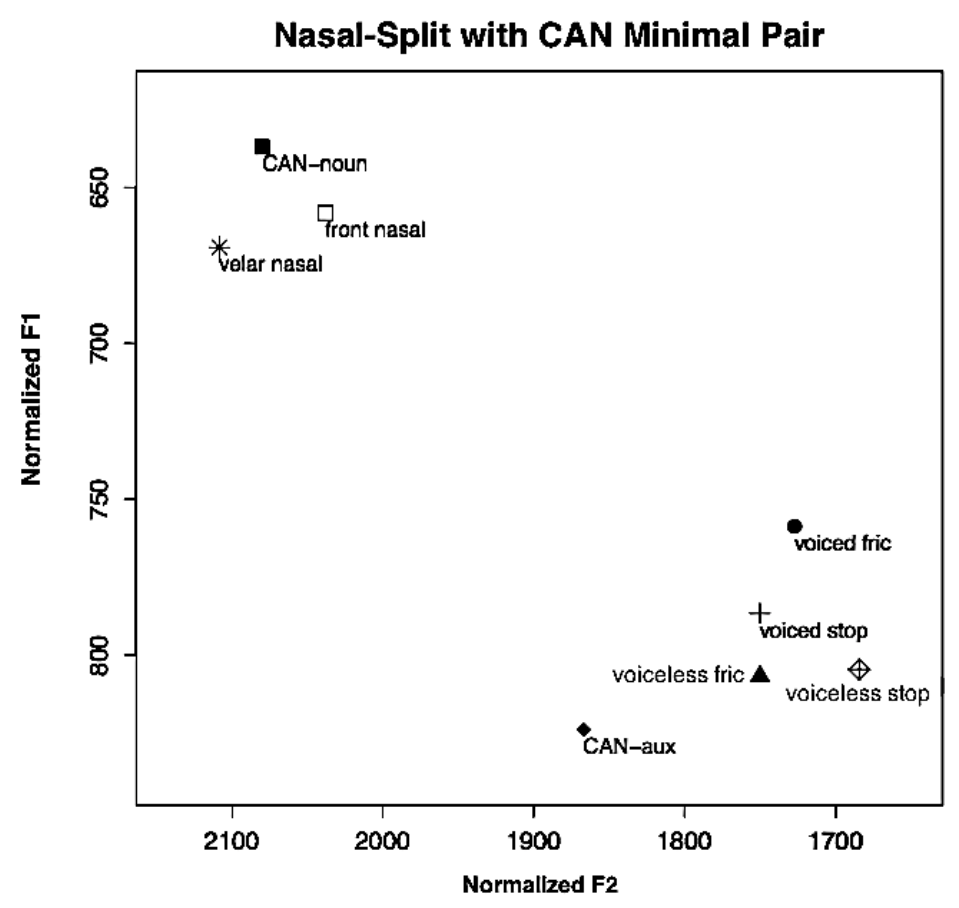

Figure 6. Vowel plot of a nasal short- $a$ split with the CAN-CAN minimal pair

5. Discussion. The data presented here shows a substantial difference between the short- $a$ splits of the students (Figure 2) and of the mentors (Figure 3) in this study. The mentors, on average, have a short- $a$ vowel system closer to the traditional NYCE short- $a$ split, with the vowels followed by voiceless fricatives and voiced stops pronounced as tense. The students have a wider variation between systems, but on average they show what's closest to a nasal-split system. The nasal-split systems that these students exhibit, however, show evidence of additional constraints persisting from the traditional NYCE complex-system. Specifically, there is evidence of the Initial Condition (where short- $a$ vowels at the beginning of a word are lax instead of tense) and the Open-Syllable Constraint (where short- $a$ vowels are lax in open syllable environments where the following segment would condition them as tense if it was tautosyllabic). This is illustrated by the placement of the PLANET and ANT word classes in the lax position on the plot in Figure 4. Additionally, a robust minimal pair is maintained between the word "can" used as a noun or as an auxiliary, even amongst the students with the most advanced transition to nasal-split (Figure 6).

This paper provides evidence of a change in progress taking place in Nassau County, Long Island, a suburban area of the New York City dialect region. The traditional NYCE complex short- $a$ split is giving way to the nasal-split that is more common in American English. The complex-split is still present in both young and older speakers in the study, but the trend is towards more young speakers exhibiting a nasal-split. This pattern is similar to what was found in other New York City area studies (Becker and Wong 2009, Becker 2010), including the identification of speakers with transitional continuous-raising systems. The present data, however, introduces an additional dimension in the progression of the change in this community, wherein phonological constraints from the traditional complex-split continue to operate on the nasal-splits of the younger speakers. 


\section{References}

Babbitt, E. H. 1896. The English of the lower classes in New York City and vicinity. Dialect Notes 1. 457-464.

Becker, Kara. 2009. /r/ and the construction of place identity on New York City's Lower East Side. Journal of Sociolinguistics 13(5). 634-658. https://doi.org/10.1111/j.14679841.2009.00426.x

Becker, Kara. 2010. Regional dialect features on the Lower East Side of New York City: Sociophonetics, ethnicity, and identity. New York, NY: New York University dissertation.

Becker, Kara. 2013. The sociolinguistic interview. In Mallinson, C., Childs, B. \& van Herk, G. (eds.) Data collection in Sociolinguistics. New York: Routledge.

Cohen, Paul. 1970. The Tensing and Raising of Short (a) in the Metropolitan Area of New York City. New York, NY: Columbia University MA thesis.

Coggshall, Elizabeth Learn. 2017. Short-a in the Sixth Borough: A Sociophonetic Analysis of a Complex Phonological System in Jersey City. New York, NY: New York University dissertation.

Kurath, Hans. 1949. A Word Geography of the Eastern United States. Ann Arbor: University of Michigan Press.

Labov, William. 1966/2006. The Social Stratification of English in New York City. Second Edition. Cambridge: Cambridge University Press.

Labov, William, Malcah Yaeger, and Richard Steiner. 1972. A Quantitative Study of Sound Change in Progress. Philadelphia: US Regional Survey.

Labov, William., Ash, S., \& Boberg, Charles. 2006. The Atlas of North American English: Phonetics, phonology, and sound change. Berlin: Walter de Gruyter.

Labov, William. 2007. Transmission and Diffusion. Language 83(2). 344-387. https://doi.org/10.1353/lan.2007.0082

Olivo, Ann Marie. 2013. The Strong Island Sound: Sociolinguistic Evidence for Emerging American Ethnicities. Houston, Texas: Rice University dissertation.

Rosenfelder, Ingrid, Joe Fruehwald, Keelan Evanini, and Jiahong Yuan. 2011. FAVE (Forced Alignment and Vowel Extraction) Program Suite.

Shapp, Allison. Forthcoming. A Sociophonetic Analysis of New York City Dialect Features on Long Island. New York, NY: New York University dissertation.

Trager, George L. 1942. One phonemic entity becomes two: the case of 'short a'. American Speech 15(3). 255-258. https://doi.org/10.2307/486966 